\title{
Active Citizenship and Subjective Well-Being Among Indonesian Millennials
}

\author{
Deena Soedikto \\ Tilburg University \\ deenasoedikto@gmail.com
}

July 8 th, 2020

\begin{abstract}
A society cannot progress without the well-being of its citizens. This study aims to assess the subjective well-being (SWB) of Indonesian millennials, mainly through their active participation in communities. Active citizenship is a form of social interaction with a blend of activism. It is not purely an act of altruism as individuals are assumed to expect gains from their social networks through civic participation. Therefore, social networks are taken into account as determinants that moderates the effect of active citizenship on SWB. Given the heterogeneous nature of the Indonesian society, socio-demographic determinants of gender, education, religiosity, and place of domicile are also expected to moderate the aforementioned relationship. The research is conducted by incorporating $318(\mathrm{~N}=318)$ respondents of the 19 - 35 years old age group, residing in Indonesia. Data is collected by using non-random and convenient sampling. Results from Ordinary Least Square (OLS) Multiple Regression analysis indicate a significant effect in the association between active citizenship and SWB. Furthermore, network density, education, and religiosity also have direct effects on SWB. With regard to the interaction effect, the analysis result indicates more frequent online interactions moderates the effect of active citizenship on SWB, in comparison to the offline interactions. Moreover, gender is another determinant moderating the association. However, both interaction variables are indicated in negative effect sizes. As implication, some of these findings are to give new insights in the current discussion on subjective well-being among Indonesian millenials, whereas other aspects are to be improved in future similar studies.
\end{abstract}




\section{Introduction}

Over the past few years, welfare and well-being are often linked to material prosperity, however, more studies are incorporating measures of happiness and subjective well-being as one of the indicators. Subjective well-being addresses at the individual level, which assesses the realm of people's feelings, while the common sociological discussion tends to be pragmatic, ideological, and theoretical (Veenhoven, 2008). Thus, it leads to the question on how the concept is integrated with other concepts in sociology. Subjective well-being serves to convey that something is connected with good feelings. Certain social conditions enhance subjective well-being which has positive effects on human functioning such as creativity, social contacts, work performance, and physical health (Lyubomirsky \& Diener, 2005; Veenhoven, 2008).

Overaching social conditions such as modernity, the welfare state, social equality, social participation, and social support are considered to foster subjective well-being (Veenhoven, 2008). Furthermore, in their study on the factors predicting subjective well-being in 55 nations, Diener, Diener \& Diener (1995) found high income, individualism, human rights, and societal equality to be correlated to subjective well-being. These studies are mainly conducted in the context of Western societies, and little amount is still available in the context of developing countries, including Indonesia. In the context of Indonesia, an existing survey conducted by Indonesian National Bureau of Statistics (2017) focused on the socio-demographic factors such as area classification, gender, marital status, age group, and place of domicile (according to province) to assess well-being. The overall result of this survey indicate an increase ${ }^{1}$ in the level of happiness among Indonesian citizens, with young people $(<24$ years old) being the happiest group. These results provide valuable intrinsic insights on the trend of happiness of Indonesian citizens. In order to further explain the sociological process, a mechanism should also be taken into account. In this study, the discussion will be directed to the notions of social participation in the form of active citizenship.

Active citizenship and civic engagement are consequences of the flourishing democracy in Indonesia. Diversifying from its counterparts of countries in the Western world which mostly are established democracy in the form of welfare states, Indonesia is an emerging democracy, still shaping its form as a nation. Exceptionally heterogeneous, the ties that binds people in Indonesian democracy is largely of its vibrant associational life (Lussier \& Fish, 2012). Based on the data from 2005 - 2008 World Values Survey, Indonesia rates in the top fifth of 49 countries in terms of organizational membership, indicating roughly 84 percent of Indonesians belong to at least one organization (Lussier \& Fish, 2012). These associational life has enabled Indonesians in sustaining self-governance through a sense of efficacy; developing and transferring civic skills that enable citizens to participate in politics effectively; and the creation of opportunities for individuals to be recruited for political participation. Furthermore, according to UNFPA (2017), young people are some of the key actors in civic engagement that contribute to the building of peace, eradication of poverty, sustainable development and intercultural dialogue. For young people, taking active participation in communities are determined by social influence, values, and instrumental

\footnotetext{
${ }^{1}$ From 62.28 in 2014 to 70.69 in 2017 , of a scale between $0-100$. Index are constructed from multiple items: Happiness Index, Life Satisfaction Index, Affection Index, and Eudaimonia Index. Survey sample size is 75.000 (households) from 487 cities/districts in 37 provinces of Indonesia. For full report https://www.bps.go.id/publication/2017/12/05/1f99cefd596c449b93405fcd/indeks-kebahagiaan-2017.html
} 
motives and in the system level, availability of community programs and organizations, norms of reciprocity, and social responsibility (Nurdiyanti \& Suryadi, 2019).

Both subjective well-being and active citizenship have been discussed somewhat extensively given the amount of existing studies available. In their study in assessing the volunteer work and well-being, Thoits and Hewitt (2001) found the relationship to be positive and linked to individual's participation in religious and secular organizations. Furthermore, Cicognani et. al. (2007), revealed how social participation among youth correlates with a sense of community and identification with community, and that social engagement is influenced by the long traditions of involvement in voluntary association and private social services in the United States. Resonating with the aforementioned findings, in their qualitative study Hall et. al. (2000) elaborate on how youth work provides young people the opportunities to develop community values as well as encouraging critical awareness of the issues which frame the broad concept of active citizenship. To some extent, these engagements in communities are absorbing individuals to be involved with tasks, in which they are challenged to apply skills yet at the same time acquiring immediate feedbacks (Zepke, 2013). Thus, there are also learning process involved in perfoming active citizenship activities. More cognitive engagement are likely to take place when individuals are intrinsically motivated to be involved as active citizens, which eventually leads to meeting their personal goals as well as achieving positive personal and social outcomes (Zepke, 2013). In a broader sense, engaged individuals can contribute to subjective well-being by enriching the workings of democracy, voicing ideas in times of uncertainty, challenging the status quo thoughtfully, constructively and decisively in a world conflicted by ethical, environmental and political dilemmas and motivate young people to become aware of themselves as active citizens and their potential to effect change in a world that is open, fluid and contested (Barnett \& Coate, 2005; Zepke, 2013).

This study will focus on the relationship between subjective well-being and active citizenship of Indonesian Millennials, taking into account the interaction effect of social capital. Furthermore, individual socio-demographic determinants will also be taken into account as the moderators. As mentioned, most of the literature available on these concepts are heavily emphasizing on the context of Western societies with established democracies. This study aims to diverge the perspectives, given the overarching contexts of the "third wave" democracy with exceptionally diverse ethnic groups and vibrant associational life. In addition to these trends are the current technological advances and globalizing of lifestyles which influence the daily conducts of Indonesians. These overarching trends are both advantages and obstacles to the nation's development, as the country still lacks crucial structural and cultural determinants of democracy (Lussier \& Fish, 2012). While the National Happiness Survey (2017) indicates that Indonesians are relatively happy, it is admissible to further and directly examine the social conditions contributing to their well-being, especially among young people. Taking all these factors into account, the output of this study will present the state of happiness of Indonesian millennials studied. This objective is to be met through different parts presented in this paper. In the second chapter, further explanation on the association between subjective well-being and active citizenship will be elaborated. This part will also comprise the discussion on the interaction effect of the social capital (network size, organizational membership, and offline/online interactions) and socio-demographic factors (gender, education, religiosity, and place of domicile). The third part of the paper will explain the research design which includes details on data and analyses used to answer the research question as well as testing the hypotheses. This part is followed by the interpretations of the research findings. Conclusion and recommendation will be presented in the last chapter. 
Does active citizenship have a positive effect on subjective well-being, taking into account the moderating effect of social capital factors (network size, organizational membership, offline/online interaction) and socio-demographic factors (gender, education, religiosity, place of domicile)?

\section{1 - Theoretical Framework}

\subsection{Subjective Well-Being : Definition, Determinants, and Consequences}

In brief, subjective well-being (SWB) is defined as 'a person's cognitive and affective evaluations of his or her life' (Diener, Lucas, \& Oshi, 2002). In his study, Diener (1984) further differentiate the concept into three categories, namely external virtues; life satisfaction; and positive affect. External virtues refers to the non-subjective state of SWB, and rather how other people (observers) made judgement based on their value framework on one's desirable qualities (Diener, 1984). The category of life satisfaction refers to one's global assessment on their quality of life according to their own criteria, particularly in relation with their desires and goals (Diener, 1984). Lastly, there is a positive affect, referring to pleasant emotional experience (Diener, 1984). Given these differentiations, there are implications on the hallmarks of SWB, which also has three areas, first it is subjective; second, it includes positive measures; and third, it includes a global assessment of all aspects of the person's life (Tov \& Diener, 2008). As an operational definition, SWB is most often interpreted to mean experiencing a high level of positive affect, a low level of negative affect, and a high degree of satisfaction with one's life (Deci \& Ryan, 2008). To the extent that one embodies these three constructs, he or she is said to be high in SWB. Moreover, given the multiple dimensions of SWB, research most often stretches on life-satisfaction and positive affect, which implications is also on the measurement of SWB (Diener, 1984).

The level of one's subjective well-being is influenced by both internal and external factors (Diener \& Lucas, 2008). Personality and outlook towards life are major internal determinants of subjective well-being, whereas society in which one lives is the major external determinant (Diener \& Lucas, 2008). The extent of one's subjective well-being is linked to their personality traits, such as self-esteem, internality, extraversion and intelligence (Tov \& Diener, 2008). As for the external factors to subjective well-being, one of the major trends has been to examine demographic determinants, which characterize people and influence their well-being. External factors related to social conditions such as material well-being, political and civic rights, social comparison, equality, and cultural homogeneity are perceived to be the macro level factors contributing to SWB (Diener, Diener \& Diener, 1995). Wealth has been repeatedly used as a determinant in predicting SWB, where the effect only applies to some extent. Veenhoven (1991); Schyns (1998); Diener \& Oishi (2000) found the correlations between income and SWB were actually stronger in poorer nations. These findings suggest that factors have varying degrees of effect on SWB. In their study, Diener, Diener \& Diener (1995), discovered patterns which suggest that efficacy in terms of meeting one's needs and the ability of pursuing goals are important cross-cultural factors in achieving SWB (Diener, Diener \& Diener, 1995). In this case, the idea of pursuing goals could be manifested in different forms. For instance, taking into account social capital to help one getting by and ahead in life through the resources available within the network, maintained in social contacts and relationships. The evidence is presented in a study by Diener (1984), which found the number of friends, number of close friends or confidants, amount of social contact as determinants to subjective well-being (Diener, 1984), and so forth. Quantity, and 
particularly the quality of friendships and social relations correlates positively with happiness, while loneliness is linked to depression (Diener \& Seligman, 2002). Moreover, the same study also revealed that social activities and participation are highly correlated with SWB, and that in some cases the effect is dependent on other individual determinants, such as education (Diener, 1984).

Age, gender, employment, education, religion, and marriage are also considered as socio-demographic determinants which contribute to subjective well-being. Early studies found that young people were happier than old (Bradburn \& Caplovitz, 1965; Gurin et al., 1960; Kuhlen, 1948; Wessman, 1957; Diener, 1984). Braun (1977) found a curvilinear relationship between age and SWB, in which younger respondents reported stronger levels of both positive and negative affect, but that older subjects reported greater levels of overall happiness. With regard to gender, women are reported to experience greater joys, especially among the younger group. Whereas men tend to be happier as they get older (Medley, 1980; Diener, 1984). Whereas religious people tend to participate in religious services and affiliations as well as cultivating relationships with God, which makes them happier (Kesebir \& Diener, 2009).

There are outcomes to well-being, both influencing at individual and collective levels. Flourishing is one of the consequences of well-being, which offers a holistic perspective on what it means to feel well and happy. As individuals flourished, well-being is being reproduced, through increased positive emotions, more engagements, developing deeper and more meaningful relationships, as well as to achieve more goals. The experience of well-being encourages individuals to pursue goals that have the capacity building in order to meet future challenges (Diener, 1984). Happy individuals are more motivated to pursue long term goals, due to the tendency of exercising self-control or delaying gratifications (Diener, 1984). Thus, happier individuals tend to be more forward-thinking and willing to consider the long term implications of decisions that are taken in the present, which leads to better decisions for themselves and the society (Diener, 1984).

\subsection{Active Citizenship, Social Capital, and Subjective Well-Being}

Active citizenship in Indonesia is mainly influenced by the several overarching trends, a lower-middle income country, predominant Muslim population, and tremendous ethnic diversity (Lussier \& Fish, 2012). Being in the "third wave" of democracy, robust democratization has been taking place, which is mainly influenced by the "unusual" vibrant associational life (Lussier \& Fish, 2012). Level of civic engagement in Indonesia is considered high. Results from the 2005 - 2008 World Values Survey (WVS) indicate the nation rates in the top fifth of 49 countries in terms of membership in formal organizations (Lussier \& Fish, 2012). Civic engagement is taking place in various levels within the society, with some which are typical and influenced by culture. Take for example the neighborhood associations, and pengajian, a religious group or organization affiliated with Muslims, which are mainly organized independently by residence for the purpose to socialize (Lussier \& Fish, 2012). In a more contemporary context, active citizenship in Indonesia has diverged into various forms. One of the emerging forms of active citizenship among young people of Indonesia is social entrepreneurship, defined as socially responsible entrepreneurship which aims to solve social problems that were left overlooked by businesses, governments, and non-governmental organizations (Zahra, et.al., 2006; Rostiani, et. al., 2014). Social enterprises have also been seen as the evolution of local non-profit, voluntary organizations and charities (Rostianti et. al., 2014). Moreover, with the context of technological advances, more participation are taking place in the digital sphere, in the forms of social movements 
such as online donation or petition. Taking example of kitabisa.com, a leading online crowdfunding platform for social causes, popular among Indonesian millennials, which has raised more than USD 36 million in the past five years (IDNTimes, 2019).

Hoskin (2006) defined active citizenship as participation in civil society, community, and/or political life, characterised by mutual respect and non-violence and in accordance with human rights and democracy. Based on this definition, active citizenship includes participatory activities, ranging from representative democracy, to participation in the everyday life of the communities (Hoskins \& Mascherini, 2006). Furthermore, these forms of participation should be ethical, and should not contravene the principles of human rights and the rule of law (Hoskins \& Mascherini, 2006). The emphasis of active citizenship is on the activities conducted by individuals or groups of individuals that contribute to the wider society in continuation of democracy, good governance, and social cohesion (Hoskins \& Mascherini, 2006). These activities play a vital role bridging divisive social cleavages, integrating people from diverse backgrounds and values, promoting 'habits of the heart' such as tolerance and cooperation, thereby contributing towards a dense, rich and vibrant social infrastructure (Barber, 2009). Some of the known purpose of active citizenship is to build understanding and trust between communities, thus there is a stronger sense of one's own culture (i.e values, beliefs, behaviors) and identity through engagement with other cultures (Barber, 2009). Through active citizenship, people are also increasing knowledge of how their local community works, thus able to take action for improvements through sustainable activities (Barber, 2009).

For young people, community participation has influences in both objective and more affective emotional level, gained through the feeling of being part of a community; being influential; fullfillment of needs; and shared emotional connection (McMillan \& Chavis, 1986; Barber, 2009). Moreover, through community participation young people are solving problems, creating mutual cooperation, ensuring compliance with established norms and alleviating the individual burden in carrying out their missions (Putnam, 2000). To summarize, active citizenship is allowing individuals to maintain or grow their social relations, which allows the mobilization of resources, as well as collectively engage in meaningful activities which are expected to have an effect on their happiness. While non-active citizens are less in gaining the benefits of social capital, therefore less happy. Thus, active citizens are likely to be happier in comparison to those who are non-active citizens. Consequently,

Hypothesis 1: Being active citizens has a positive effect on subjective well-being

\subsection{The Role of Social Networks - Density, Organizational Membership, and Offline Interactions}

Initially understood as goods which produce commodities for production, the notion of capital eventually transferred into the realms of social relationships and social network (van Der Gaag, 2009). Thus, when a person owns social capital, it implies to the resources owned by the network members, generated through his/her social relationships and with expected returns (van Der Gaag, 2009). One of the principles for resources to be generated is that one does not simply give them away to others, thus there are conditions which allow mobilization to take place. Within the discussion of social capital, these conditions are trust and reciprocity (van Der Gaag, 2009). The former refers to the conviction that other people will return the favors given, while the latter refers to a sense of balance in the exchange of resources between two or more parties (van Der Gaag, 2009). Given these mechanisms, people will 
intentionally invest in their social relationships if future benefits are perceived and to take the expected values as motivation for action (van Der Gaag, 2009). In a broader sense, there are normative structures which dictate how social relations and exchanges should be organized, and they vary over countries, cultures, and religious traditions (van Der Gaag, 2009).

Social capital can be embodied in bonds among family, friends and neighbours, in the workplace, at church, in civic associations, perhaps even in internet-based 'virtual communities' (Helliwell \& Putnam, 2004). Thus, social capital is implemented in cooperative activities within and among groups of individuals. Similarly, active citizenship also refers to a sense of belonging and solidarity for the community, often started by initiatives of taking proactive measures in recognizing existing problems, which at the same time also requires collective action for carrying out missions and making impact (Barber, 2009). In the realm of active citizenship, the cooperative activities are taking place among individuals who are interested in the current affairs happening in their local communities (Barber, 2009). To some extent, there is similarity between the terms of social capital and active citizenship (Hoskins \& Mascherini, 2006). In general social capital refers to the 'power or social advantage' (Baron et al. 2000) gained by individuals through their social networks, therefore reciprocal relationships are developed within these social networks (Putnam 2000; Hoskins \& Mascherini, 2006). Thus, discussion on social capital typically focuses on the working of networks in participation and how these networks can be utilized (Hoskins \& Mascherini, 2006). Whereas active citizenship does not refer to the networks created through participation, instead the actual engagement and societal gain through these actions (Hoskins \& Mascherini, 2006).

In the next paragraphs, the discussion will be directed towards the moderating effect of social capital in the association between active citizenship and subjective well-being. In this case, social capital is explained in the form of network size, organizational membership, and offline/online interactions.

\section{Network Size}

Hall (1998; 2000); Frazer \& Emler (1997) described the "third way" of citizenship indicated by the increasing communitarianism, which its critical importance is on the intermediate reference points between individuals, families, associations, workplaces, and the community. Community is the central in the communitarian perspective of citizenship, focusing on the values of solidarity and participation in the community as crucial to the realisation of a 'good society'(Hall et. al., 2000). Communitarianism thus recognizes how individuals are embedded in various social sites, in which network of obligations and privileges are united (Hall et. al., 2000). These social sites strengthen communities in which civic activism, mutuality and social capital are taking place, conditioning for social inclusion and prosperity (Hall et. al., 2000). The involvement of young people is not solely to have a sense of community, but also to develop practice of youth work by participative activity and community involvement (Hall et. al., 2000). Through this process, young people are acquiring skills and competencies through experiential learning, implemented in various forms, such as volunteerism (Hall et.al., 2000). These learning processes are enabled by sharing mutual values such as respect, social awareness, responsibility, etc (Hall et. al., 2000) which are also crucial for maintaining social relationships and networks.

Within networks resources are embedded, and being attained by social relationships, which could be formal or informal (Putnam, 2000; van Der Gaag, 2005). These relationships are shaping the density of one's network, which refers to the degree to which all people in a 
given social network are connected to each other (Burt, 2000; van Der Gaag, 2005). People who have variations in network density are likely to increase the likelihood of having a certain quantity or quality of the resources embedded. People who have frequent contacts with family, friends and neighbours are shown to have higher subjective well-being than others with no such contacts (Helliwell \& Putnam, 2004). Social capital can be embodied in bonds among family, friends and neighbours, in the workplace, at church, in civic associations, perhaps even in Internet-based 'virtual communities' (Helliwell \& Putnam, 2004). Furthermore, the presence of social trust, norms of reciprocity and trustworthiness are a nearly universally concurring of these dense social networks (Helliwell \& Putnam, 2004). Similarly, Coleman (1990) also argues that social networks with high 'connectedness' are beneficial, if people in a group know each other, they can share the same normative system and have a more effective sanctioning system, which contributes to trust and the actual mobilisation of potential support.

Through the perception of acquiring and making use of social capital (network and connections), people are engaged in active citizenship activities (Zepke, 2013). Being engaged in active citizenship activities is thus perceived as individual choice based on the perception of gaining advantage or benefits (Zepke, 2013). The chance of gaining these benefits are likely to be higher among those with bigger network size as they perceive more opportunities to access from the available pool of contacts and relatives, in comparison to those with fewer network sizes. Consequently,

Hypothesis 2: The relationship between active citizenship and subjective well-being are stronger among millennials with high network size, compared to those with fewer network size

\section{Organizational membership}

Groups of volunteers coming together in building communities by making improvements, while at the same time developing bonds of social capital. Tocqueville (1835, p.492) acknowledged how the affinity of forming organizations is provided by the "art of associating". Through the formation of organization, people are gathered collectively as well as gaining the benefits of developing civil skills (Green \& Brock, 2005). Some organizations participation might require time or financial commitment, thus more likely limited to the higher socioeconomic class, while some organizations are also taking the role of bringing diverse groups of people together, i.e of various age, race or ethnic groups, and socioeconomic status (Green \& Brock, 2005). Aligning with the communitarian perspective, associations and organizations are also by product of people's solidarity and participation in supporting each other, preferably based on common interest (Hoskins \& Mascherini, 2008). Thus, organizations provide organized form of participation which addresses various components within the society (i.e religious, business, cultural, social, sport and parent-teacher organisations) (Hoskins \& Mascherini, 2008).

Beyond its formal form in providing associational bonds between individuals, organizations could also help in forming informal relations between individuals outside of their obligations (Green \& Brock, 2005). Associations foster robust norms of reciprocity and facilitate communication and improve the flow of information about the trustworthiness of individuals (Siisainen, 2000). Through associations, reputations are transmitted and refined; and, embodies past success at collaboration, which can serve as a culturally-defined template for future collaboration (Siisainen, 2000). By taking participation in civic organization, young people are gaining many developmental benefits, such as social skills (Mahoney, Cairns, \& Farmer, 2003; Pearce \& Larson, 2006), initiative and teamwork (Larson, Hansen, \& Walker, 2005), and increased educational attainment (Eccles \& Barber, 1999; Mahoney, Larson, 
Eccles, \& Lord, 2005; Marsh \& Kleitman, 2002). By participating in civic organization, young people are also improving their credentials for college admission or a career (Hansen \& Larson, 2006; Lauver \& Little, 2005; Pearce \& Larson, 2006).

Looking at the relative roles of organization, there are both formal and informal functions, which to some extent serves a distinct purpose in the framework of 'community membership'. Being a member of an organization is an act of active citizenship, which at the same time associational functions are taking place. Through these functions, individuals are engaged with each other, while allowing exchange of resources. One could be affiliated with one or more organizations, yet not contributing actively, thus having less gain from their affiliation. For instance, a person might be affiliated with an organization since he/she is regularly giving support in the form of donation, whereas active organization members frequently engage collectively in activities to help move their mission forward. Thus, individuals who are active members of an organization are likely to have more gains for subjective well-being through direct engagements in comparison to those who are less active or non-members. Consequently,

Hypothesis 3: The relationship between active citizenship and subjective well-being are stronger among active organization members than who are non-active members

\section{Offline/online interactions}

A contemporary approach to active citizenship is moving towards the digital sphere. According to theorists, digital citizenship allows the creation of social impact through the mobilization of individuals to be involved in collective activities, taking place both online and offline (Nurdiyanti \& Suryadi, 2019). The concept of digital citizenship refers to civic engagement which is characterized by online behaviors (of online citizens in carrying out online activities) and online civic engagement (referring to individual participation in community affairs through online media) (Yang, H.H et. al., 2018; Nurdiyanti \& Suryadi, 2019). The vast amount of information available on the web and the ease of using search engines to find groups fitting one's interest enables newcomers to find, join, and become involved in kindred organizations (Lin, 1999; van Der Gaag, 2005). Furthermore, another key element to this process is the presence of collective identities, in which individuals group themselves based on common interest, values, feelings and goals (Hunt \& Benford, 2004; Nurdiyanti \& Suryadi, 2019). In the context of Indonesia, these underlying values are important for the effectiveness of digital citizenship, in addition to collective identity, there are also solidarity and commitment towards one another (Nurdiyanti \& Suryadi, 2019).

The Internet and the new digital platforms of communication are often associated with rising individualism and linked several consequences for social relationships. Some scholars argue that given the abundance of social interactions on the Internet, social relationships are becoming more superficial (Turkle, 2011; Vriens \& van Ingen, 2018). The characteristics of networks taking place online tend to be loose ties, meaning that more acquaintanceship are present, which tend to provide bridging, instead of bonding social capital (Ellison et. al. 2007; Manago \& Vaughn, 2015). Skepticism on online engagement arouse due to the connections established are lack the kind of depth, authenticity, and genuine trust that comes from face-to-face interactions (Soraker, 2012; Manago \& Vaughn, 2015). Lin (1999) pointed out that most relationships formed in cyberspace continue in physical space, leading to new forms of community characterized by a mixture of online and offline interactions. Similarly, van Der Gaag (2005) argues that if the internet increases social capital, then high internet use should be accompanied by more offline interpersonal contact, organizational participation, 
and commitment to community. Thus, the internet is a supplement to social capital, that is more useful for maintaining existing ties than creating a new one (van Der Gaag, 2005). In their study on Canadian context, Helliwell \& Huang (2013), found a more straightforward notion that real life interactions are associated significantly to subjective well-being, while the correlations are zero to negative with online interaction/friendship. No studies yet found on the context of Indonesia with regard to online interaction and subjective well-being.

To summarize, both online and offline interactions have consequences on how active citizenship is being practiced. Given the expansive nature of the internet, social movements are able to reach a wide audience in a rather swift manner. Internet and social media use among Indonesians are relatively high, as there are reported around $130^{2}$ million Facebook accounts owned by Indonesian, as per January 2018 (The Jakarta Post, 2018). Through these platforms, young people are being interconnected across borders, allowing more collective collaboration. Online interactions are actually rewarding other forms of gains, such as wider acquaintances, effective communications, increasing velocity in exchanges of resources (i.e information, knowledge). For Indonesian millennials generation, the internet is a valuable medium to gain and exchange resources for self-development and getting ahead in life. Thus, it is expected that the effect of active citizenship on subjective well-being will be higher among those frequently interacting online. Consequently,

Hypothesis 4: The relationship between active citizenship and subjective well-being are stronger among those who are more often interacting offline compared to those who are more often interacting online

\subsection{Individual socio-demographic determinants (gender, education, religiosity, and place of domicile)}

Individual attributes are also linked to the degree of their subjective well-being in association with social capital and active citizenship. The attributes that have been shown in many studies to be predictive of subjective well-being are marital status, race, education, employment and age (Glenn \& Weaver 1985; Gove \& Shin 1985; Gove et al. 1985; Coombs 1991; Clark \& Oswald 1994; Clark et al. 2003). An early review of the literature nearly four decades ago profiled the happy person as 'young, healthy, well-educated, well-paid, extroverted, optimistic, worry-free, religious, married person with high self-esteem, job morale and modest aspirations, of either sex and of a wide range of intelligence' (Wilson 1967, p. 294, quoted by Diener et al. 1999). Highly attributed individuals tend to have high feelings of well-being, thus are more likely to be successful in a variety of life domains, including health and longevity, work and income, and rewarding social relationships.

\section{Gender}

Graham and Chattopadhyay (2012) use the Gallup World Poll to investigate gender issues in well-being. They find that women are generally happier than men, but that the relationship is strongest for high income countries and there is no significant difference in low income countries (Zweig, 2014). Studies on gender and happiness found men and women were socialised to express different emotions. Women are more likely to express happiness, warmth and fear, which helps with social bonding and appears more consistent with the traditional role as primary caregiver, whereas men display more anger, pride, which are more

\footnotetext{
${ }^{2}$ The number comprises more than half of the total Indonesian population, which is 237.641 .326 as per 2010 (Indonesian National Bureau of Statistics https://sp2010.bps.go.id/ )
} 
consistent with a protector and provider role (Zweig, 2014). Moreover, according to feminist theorist, compared to men, women speaks and act in ways that are more altruistic, more communal, and more nurturing, which are influenced by maternal thinking (Schlozman et. al, 1995). Women's participation are more likely to be based on the concerns of the good of the community; on issues related to children and families; human welfare; environmental concerns; international peace (Schlozman et. al, 1995). Thus, it is expected that men and women bring distinctive concerns to active participation and to support and specialize different kinds of activities. Furthermore, Schlozman et. al, (1995), studied the benefits (material, social gratification, and civic gratification) gained between male and female with regard to their citizenship participation. Result of the study indicates the differences are neither very substantial in magnitude nor consistent across gratifications, thus little difference there is between men and women in terms of benefits gained by taking active participation. To conclude, women's participation are more influenced by their natural tendencies to be altruistic and nurturing of others, which leads to a sense of happiness and satisfaction. Thus, women active citizens are happier in comparison to men active citizens. Consequently,

Hypothesis 5: The relationship between active citizenship and subjective well-being is stronger among women than men

\section{Education}

One of the purposes of active citizenship is to support the development of knowledge society while sustaining social cohesion (Hoskins et. al., 2008). By participating as active citizens, individuals cultivate skills and competence related to the civic realm, such as civic knowledge, skills, attitudes, and values (Hoskins et. al., 2008). Active citizenship facilitates individuals through informal learning, through organizational or associational membership, volunteering activities, etc. In parallel with informal learning, the extent on how active citizenship has an effective effect on individual social outcomes are also influenced by other parties who support the learning process, such as peers, family, and the community (Hoskins et. al., 2008). Another important determinant in assessing the relationship between active citizenship and education is one's socio-economic background (Hoskins et. al., 2008). For example, in their research, Spring et.al, (2007) found that civic and political participation are lower among young people of lower socio-economic, while it is higher among young people coming from wealthier, higher educated families (Wood, 2013; McFarland \& Thomas, 2006).

In his concept of 'theory of practice', Bourdieu (1977) explained how citizenship participation as a socially embedded practice that is influenced by habitus and capital held by individuals and groups. These capitals could refer to cultural aspects of knowledge, skills, and information which people acquire. Earlier studies found that formal educational attainment during adulthood leads to status attainment which leads to an increase in the quality of life (Witter et. al, 1986). Furthermore, other studies indicate the non-material gains of people who have higher levels of education in comparison to those with lower education. In their study, Yakovlev \& Leguizamon (2012) found a relatively strong positive effect of education on subjective well-being. In a deeper notion, Sanford (1956) found that highly educated people are more likely to developed "help-seeking" orientation toward mental health problems than do less educated people. Having their self-efficacy fulfilled to some extent, both in material and nonmaterial aspects, individuals with higher education are likely to maintain their cultural and social capital. Among young people, active citizenship allows them to generate resources as a result of social connections and relationships, and thus it is considered to facilitate the type of co-operative social relations that are important for collective action (Wood, 2013; Fahmy, 2006). 
Difference on the level of subjective well-being is expected between people of various education levels. It is partly explained by the feelings of personal efficacy, including the capability of assessing one's mental state (Warr, 1978; Yakovlev \& Leguizamon, 2012). In addition to the immaterial aspect, people with higher education are more likely to be more resourceful. Educated individuals are able to serve for a greater good by utilizing the set of skills and knowledge which they possess. Thus, they are more likely to gain a sense of life fulfillment through their active participation, in comparison to those who are less educated. Consequently,

Hypothesis 6: The relationship between active citizenship and subjective well-being are stronger among more educated than less educated millennials

\section{Religiosity}

A Muslim majority country, the extent of citizen participation among Indonesians is somewhat influenced by religious values. One of the early social scholars, Ibn Khaldun, in his Al - Muqaddimah postulated the concept of 'asabiyah or social solidarity, which was derived from the idea that human being by nature is a social being who prefer to live together, cooperate and helping each other (Ibn-Khaldun, 1995; Dusuki 2006). Putnam (2000) confirmed that religion is considered to be an essential element of civic engagement. Social support is more likely to be "received and interpreted in the spirit in which it is intended" when provided by someone with whom the recipient shares a sense of social identity (Haslam et al. 2009; Lim \& Putnam, 2010). Ellison \& George (1994) propose that churchgoers may derive a greater sense of comfort from their co-religionists because they have similar beliefs about the practice and meaning of helping behavior.

Religiosity has broad dimensions which encompasses the dimensions of institutionalized/interiorized religion; substantive function of religious practice and beliefs; and positive-negative evaluations of religion (Pargament, 1999). Conceptually, there are strong reasonings on why religiosity promotes subjective well-being across cultures, as there are evidence showing inherent universal human needs (i.e belonging) that enhance subjective well-being when fulfilled (Maslow, 1943 ; Ryan \& Deci, 2000 ; Tay \& Diener, 2011). Studies suggest that strong religious faith and personal spiritual experiences can improve well-being by bolstering self-esteem and self-efficacy (Ellison 1991; Lim \& Putnam, 2010). In many studies, frequency of religious service attendance is the most consistent correlation of subjective well-being (Ferriss 2002), although several studies find that inner or spiritual dimensions of religion are also related to well-being (Ellison 1991; Greeley \& Hout 2006; Krause 2003; Lim \& Putnam, 2010).

Religiosity is perceive to enhance the association between active citizenship and subjective well-being, and difference in effect is expected between the religious and less religious. Religious individuals are able to fulfill fundamental self-needs, such as self-esteem, control, uncertainty reduction, and meaning (connected with the individual self), attachment (connected with the collective self), and social belonging (connected with the collective self) (Tay et. al., 2014). These qualities are crucial factors which reinforce individual's active participation in their communities. Given both the intrinsic and extrinsic dimensions of religiosity, higher sense of solidarity and caring of others will emerge by participating in active citizenship activities. Thus, more religious active citizens are more likely to have sense of life fulfillment, in comparison to less religious active citizens. Consequently,

Hypothesis 7: The relationship between active citizenship and subjective well-being are stronger among religious than non-religious millennials 


\section{Place of domicile}

With regard to community involvement, there are expected differences between its implementation in cities and rural areas, given the contextual factors. In their study, Lussier and Fish (2012) confirmed that associational life is exceptionally rich in Indonesia, based on the measurement of organizational membership and social interaction. These activities serve as an economic function, bringing together neighbors for an evening of swapping news, as well as neighborhood clean-up and maintenance. Most of the activities are more likely to take place in rural and villages areas and being held periodically, therefore social pressure to participate is high. Individuals who participate in voluntary activities become part of a collective effort in which they can see the utility of their contribution to the whole group (Lussier \& Fish, 2012). Whereas in bigger cities, formal active citizenship are taking place in the form of voluntary association, in medium to large size organizations (Milligan \& Fyfe, 2005). Moreover, voluntary associations and organizations running in big cities are more likely to gain external support (i.e funding, expertise) from both businesses and government, thus are more likely to expand their social impact into a wide range of social groups (Milligan $\&$ Fyfe, 2005). Involvement is thus more structured, with certain levels of requirements (i.e skills, knowledge) of its members.

According to the results of the Survey of Happiness conducted by the National Bureau of Statistics (2017), people living in cities are slightly happier than people living in rural areas, with an index of 73.46 for the former, and $70.77^{3}$ for the latter. In big cities where relations are more loosely knit and the youth are more educated and generally coming from middle-upper class, engagements tend to be conducted through exchanges of resources (i.e knowledge, skills, attitude, etc). These exchanges of resources could happen between individuals of cross organizations, groups, companies, etc. Bridging networks entail cross-cutting networks (Kapucu 2011) which focus on external relations and generate reciprocal relations between different groups of society (Putnam 2000); Kapucu, 2011). According to Vriens \& van Ingen (2018), the geography of social relations has changed, where nowadays there are more associations with dispersed subgroups of people. Moreover, networks seem to consist of shifting sets of friends, resulting in more fluid and dynamic networks (Rainie and Wellman, 2014), and more "loose connections" (Van Ingen and Dekker, 2011; Wuthnow, 1998; Vriens \& van Ingen, 2018). These loose connections are translated as acquaintances owned by individuals, in which they could reach for the exchange of resources.

To conclude, individuals living in cities are more exposed to a wider group of people in order to expand their network by practicing active citizenship, thus have a greater chance to gain resources which are beneficial for getting by and ahead. Thus, active citizens living in cities are happier in comparison to those living in rural areas. Consequently,

Hypothesis 8: The relationship between active citizenship and subjective well-being are stronger among those living in big cities than those living in small cities

\footnotetext{
${ }^{3}$ From scale between $0-100$
} 


\section{Conceptual models}

Active Citizenship

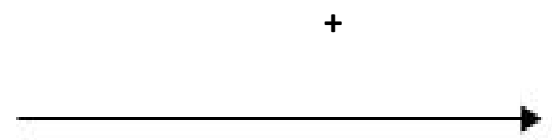

Subjective Well-Being

$$
\begin{gathered}
\text { Network density } \\
\text { Organizational membership } \\
\text { Interaction (online) } \\
\text { Gender (Women) } \\
\text { Education level } \\
\text { Religiosity } \\
\text { Domicile (Big city) }
\end{gathered}
$$

\section{2 - Research Design and Analysis}

\subsection{Data \& Operationalization}

Data will be collected for this research. Respondents are selected from the population of Indonesian Millennials (referring to individuals aged between 19 - 35 years old). In addition to the population criteria are those residing in Indonesia. Data were collected through online questionnaires between December 2019 - March 2020, by referring to existing online directories of youth organizations (i.e komunita.id, indorelawan.org, Platform Usaha Sosial), personal contacts, and social media networks. The questionnaires were distributed through emails, WhatsApp, and social media. Of the total respondents, $42.1 \%$ are male $(\mathrm{n}=134)$ and $57.9 \%$ are female $(n=184)$. With regard to level of education, $69.5 \%$ of the respondents obtained Bachelor's Degree $(n=221)$, followed by High School Degree $(15.7 \%, n=50)$, Masters Degree $(13.5 \%, n=43)$, and Doctoral Degree $(1.3 \%, n=4)$. Moreover, $63.7 \%$ of the respondents resides in the island of Java $(n=200), 10.2 \%$ in the islands of Bali and Nusa Tenggara $(n=10.2 \%), 8.2 \%$ in the island of Sulawesi $(n=26)$ and Kalimantan $(n=26), 7 \%$ in the island of Sumatera $(n=22)$, and $2.5 \%$ in the island of Papua $(n=8)$.

Table 1. Frequencies number of respondents represented from Indonesian major islands

\begin{tabular}{llc}
\hline Island & $\mathrm{N}$ & Percentage \\
\hline Bali and Nusa Tenggara & 32 & 10.1 \\
Borneo (Kalimantan) & 26 & 8.03 \\
Celebes (Sulawesi) & 25 & 8.03 \\
Java & 200 & 63.7
\end{tabular}




\begin{tabular}{lcc} 
Papua & 8 & 2.5 \\
Sumatera & 22 & 7 \\
\hline $\mathrm{N}=313$ & & \\
\hline
\end{tabular}

Non-probability and convenience sampling is used for research data collection. Non-probability sampling refers to a technique where the odds of any person being selected for a sample cannot be calculated, the opposite to probability sampling where the chance of an individual to be selected is known. In this study, the type of non-probability sampling used is the convenience sampling, which suggests a sample collection from somewhere convenient to the researcher. Some of the advantages of the non-probability approaches is that it is cost-efficient, requires less time, and used when it is restricted to conduct the probability sampling. On the down side, with this type of sampling, it is difficult to know how much the population is represented.

The sample size included in this study is $318(\mathrm{~N}=318)$ from the actual gathered responses of 350. Some responses were excluded after checking for age and domicile criteria (some respondents reside outside of Indonesia).

\section{Dependent Variable (Subjective Well-Being)}

A number of validated self-report measures of happiness, affect, and life satisfaction are in common usage, including the Satisfaction with Life Scale (Diener et al., 1985), Positive and Negative Affect Scale (Watson et al., 1988), and Subjective Happiness Scale (Lyubomirsky and Lepponer, 1999). These scales have been used in various researches, targeting various age-groups. One of the most frequently used measures is the Satisfaction with Life Scale (SWLS). Since there are still a few references on the application to these measures in Indonesian context, a little could be told on the validity and reliability, particularly on the studies targeting young people. Therefore, the safe method is by using measures from existing national scale surveys.

This study will adapt the Subjective Well-Being measure used in the national Well-Being Survey 2017 conducted by Badan Pusat Statistik (BPS) Indonesia/ Indonesian Central Bureau of Statistics. There are 12 items used to measure subjective well-being,: "Happiness in living everyday life" (scale 1 - 8); "Worry/anxiety in living everyday life" (scale 1 - 8); "Pressure in living everyday life" (scale 1 - 8), "The ability to accept whatever conditions are experienced" (scale 1 - 8); "Optimism with the future" (scale 1 - 8); "The ability to make decisions for myself" (scale 1 - 8); "Helpful for others" (scale 1 -8); "The ability to create conditions that are comfortable for myself" (scale 1 - 8); "Consistent/resilient in trying to develop own potentials" (scale 1-8), "Happiness towards life as a whole" $(1-8)$. These items are being measured in scales between $1-8$, with lower scores indicating lower level of well-being. Moreover, based on the factor analysis performed on these items, there are two underlying factors being extracted. These results provide better insights on the different dimensions constructing the SWB scale included in this study. For the purpose of further analysis, a means scale variable of SWB will be created from the items belonging in one dimension of the factor analysis (life satisfaction, optimistic with the future, making decision for own self, helpful for others, ability to create comfortable conditions, resilient in 
developing own potentials, happiness towards life as a whole). Reliability test is performed on all of these items altogether, indicating Cronbach Alpha of 0.883 .

Table 2. Factor Analysis on Subjective Well-Being items

\begin{tabular}{lll}
\hline & 1 & 2 \\
\hline Life Satisfaction & 0.808 & \\
Optimistic & 0.792 & \\
Persistence for self-development & 0.792 & \\
Creating own comfort & 0.779 & \\
Happy & 0.725 & 0.311 \\
Able to make own choice & 0.657 & \\
Beneficial for others & 0.678 & \\
Anxious to live everyday life & & 0.855 \\
Pressure to live everyday life & & 0.862 \\
Accepting any conditions & 0.418 & 0.572 \\
\hline
\end{tabular}

Extraction Method: Principal Component Analysis

Rotation Method: Varimax with Kaiser Normalization. ${ }^{\mathrm{a}}$

\section{Independent Variable (Active Citizenship)}

Hoskins \& Mascherini (2006) classified active citizenship into four dimensions : protest and social change, community life, representative democracy, and democratic values. Protest and social change refers to activities that are sometimes referred to as unconventional forms of participation such as protests, demonstrations, and political strikes. It also refers to participation or volunteering in activities organized by civil society organizations that works towards government accountability and positive social change. Community life refers to community membership, valuing solidarity and participation as realization of 'good society' (i.e participation in cultural or religious organizations). Representative democracy refers to representation in liberal model of democracy and making decisions for groups or 'the people', indicated by voting, participation in political parties, and women representation in parliament.

Synthesizing from the aforementioned dimension, active citizenship is thus operationalized on the following questions/items : involved in any volunteering activities (in the past 3 months, did you involved in any volunteering activities? - i.e in organization, residential neighborhood, school/university, work place); giving donations (in the past 3 months, did you give for donation?); signing petitions (in the past 3 months, did you sign for any petition to support social issues? - environment, corruption, justice, gender, etc); involved in any cultural activities (in the past 3 months, did you involved in any cultural activities? - i.e education, literation, art, etc); involved in any religious activities (in the past 3 months, did you involved in any religious activities? - i.e recitation, community service, etc); involved in 
any political activities (in the past three months, did you get involved in any political activities? - i.e political organization, political party, local/national election committee, etc) ; own/support social enterprises (in the past 3 months, did you get involved with any social enterprise activities? - i.e initiator, members, partners, etc). Responses range from none (0), once (1), and more than once (2). Factor analysis was performed on the items measuring the independent variable, resulting in one underlying factor that can be explained from the variables. Reliability test is performed on all of these items altogether, indicating Cronbach Alpha of 0.690. For the purpose of further analysis, a means scale variable of Active Citizenship will be created from the 7 items of measurements above.

Table 3. Factor Analysis on Active Citizenship items

\begin{tabular}{ll}
\hline & \multicolumn{1}{c}{1} \\
\hline Petition & 0.529 \\
Donation & 0.390 \\
Volunteering & 0.705 \\
Religious activity & 0.538 \\
Social enterprise & 0.759 \\
Politics & 0.564 \\
Cultural activity & 0.634 \\
\hline
\end{tabular}

Extraction Method: Principal Component Analysis.

Rotation Method: Varimax with Kaiser Normalization. ${ }^{\text {a }}$

\section{Moderating Variables}

Moderating variables are also incorporated in this study in order to test interaction effects meaning the effect of the main independent variable on dependent variable changes depending on the level of other independent variables. In the case of this study, the effect of active citizenship on subjective well-being is assumed to be changing given one's network density, organizational membership, offline/online interaction, gender, level of education, religiosity, and place of domicile.

To operationalise the item on network density, the following were asked: estimate number of relations, in this case refers to study/work colleague, neighbours, relatives, etc (if estimated, how many relations do you have?) responses ranges $0=<50$ people, $1=50-100$ people. $2=$ $>100$ people. Offline or online interaction is being measured by the following question (Where do you most often interact with your relations?) responses are $0=$ online, $1=$ residential neighborhood/ work or study environment/ community gatherings/ organization/ business. Moreover, for belonging to an organization, the following were asked: belonging to an organization (are you currently an active member of an organization?) responses between $0=$ no, 1 = yes. Whereas the items on individual socio-demographic are: gender (male-0/female-1); level of education (high school degree-0, Bachelors Degree-1, Masters Degree-2, and Doctorate Degree-3); sense of religiosity (do you always carry out religious 
obligations? - i.e praying, reciting Koran, bible, etc) responses ranges from $0=$ never, $1=$ rarely, 2 = often, and 3 = always; the place of residence (rural-0, city-1), the distinction were made based on the city/rural criteria by Indonesian National Bureau of Statistics.

\subsection{Method}

The statistical analysis will be composed of first descriptive statistics related to the level of subjective well-being of the respondents, as well as other contributing variables of this study. Further, to test the correlation between active citizenship variable, Social capital variables, and subjective well-being variable, a Pearson's correlation test will be performed. Correlations coefficient will show the degree of relationship between these variables.

In order to analyse the relation between IV and DV, an Ordinary Least Square (OLS) analysis will be performed. The estimation of the first model (Model 1) with active citizenship as the predictor. The second model (Model 2) will also include the explanatory variables of network density, organization membership, offline interaction, gender, level of education, religiosity, and domicile. Lastly, the third model (Model 3) variables on the interaction effect will be added, thus the analysis will include all main effects and interaction effects of the explanatory variables altogether. An extended regression analysis with 10 models will also be performed, in order to further test for multicollinearity.

\subsection{Descriptive Statistics}

The initial information to be retrieved from the dataset is the descriptive statistics including all of the variables being studied. This analysis is purposed to describe, show, or summarize data, thus allowing to see patterns that might emerge. The information provided also allows simple interpretation of the data.

Table 4. Descriptive statistics of all variables

\begin{tabular}{lllll}
\hline Variables & N & Min. Max. Mean & $\begin{array}{l}\text { Std. } \\
\text { Deviation }\end{array}$ \\
\hline
\end{tabular}

Dependent Variables

Subjective Well-Being (SWB)

$\begin{array}{llll}318 & 1 & 8 & 6.50\end{array}$

0.97

Independent Variable

Active Citizenship

$\begin{array}{llll}318 & 0 & 2 & 0.94\end{array}$

\section{Moderating Variables}

Network Size

Online/Offline interaction (Online)
0

2




\begin{tabular}{llllll} 
Gender (Female) & 318 & 0 & 1 & 0.58 & 0.49 \\
Education & 318 & 0 & 3 & 1.00 & 0.58 \\
Organization membership (Member) & 318 & 0 & 1 & 0.67 & 0.46 \\
Religiosity & 318 & 0 & 3 & 2.33 & 0.79 \\
Place of Residence (City) & 314 & 0 & 1 & 0.73 & 0.45 \\
\hline
\end{tabular}

From the data presented above, the general subjective well-being of respondents are relatively high $\left(x^{-}=6.50\right.$, on a scale $\left.1-8\right)$. With regard to their active citizenship involvement, most of the respondents are in the middle spectrum $\left(x^{-}=0.94\right.$, on a scale $\left.0-2\right)$. With regard to social capital variables, the average respondents have around 50-100 relations within their network $\left(\mathrm{x}^{-}=1.23\right.$, on a scale $\left.0-2\right)$. More than half of the respondents are members of organizations $\left(x^{-}=0.67\right)$ and are more often to interacct offline $\left(x^{-}=0.67\right)$. With regard to the socio-demographics items, the level of religiosity is relatively high $\left(x^{-}=2,33\right.$, on a scale $0-3)$, and more people are living in cities $\left(x^{-}=0,73\right)$ than rural areas.

\section{3 - Research Findings}

This part of the study will test and reveal the core analysis based on the hypotheses formulated in the second part of the paper. For this purpose two types of analyses will be performed, which are Pearson's Correlations, and Ordinary Least Square (OLS) multiple regression.

\subsection{Pearson's Correlation (Active citizenship, social capital, and subjective well-being)}

Pearson's correlations is a statistical analysis performed which describes the degree of relationship between two variables. In other words, this is a bivariate analysis which measures linear correlations between variable $\mathrm{X}$ and $\mathrm{Y}$. In this analysis, items measuring active citizenship, social capital and subjective well-being are included. Results from Pearson's correlations are the effect sizes, ranging between -1 to +1 , and should significantly different from zero.

Table 5. Pearson's Correlations

\begin{tabular}{lcclll}
\hline & $\begin{array}{l}\text { Active } \\
\text { citizenship }\end{array}$ & $\begin{array}{l}\text { Network } \\
\text { size }\end{array}$ & $\begin{array}{l}\text { Organizational } \\
\text { membership }\end{array}$ & $\begin{array}{l}\text { Offline } \\
\text { interaction }\end{array}$ & $\begin{array}{l}\text { Subjective } \\
\text { well-being }\end{array}$ \\
\hline $\begin{array}{l}\text { Active } \\
\text { citizenship }\end{array}$ & 1 & $0.303^{* *}$ & $0.443^{* *}$ & 0.082 & $0.282^{* *}$ \\
$\begin{array}{l}\text { Network size } \\
\begin{array}{l}\text { Organizational } \\
\text { membership }\end{array}\end{array}$ & 1 & $0.112^{*}$ & 0.056 & $0.321^{* *}$ \\
& & & 1 & $0.162^{* *}$ & $0.155^{* *}$
\end{tabular}


Offline

interaction

Subjective

well-being

**Correlation is significant at the 0.01 level (2-tailed)

*Correlation is significant at the 0.05 level (2-tailed)

As presented in the table above, results from Pearson's correlations analysis mostly indicate a positive yet small effect size on the relationship between active citizenship and subjective well-being $(\mathrm{R}=0.249)$. Furthermore, to see the extent of the relationship between active citizenship and social capital, the latter variable is analyzed in three items, namely network density, organizational membership, and offline/online interaction. The effect size is significant for network density $(\mathrm{R}=0.303)$ and organizational membership $(\mathrm{R}=0.443)$. This indicates that active citizenship is associated with one's network size, as well as being a member of an organization. Moreover, with regard to the effect size between social capital and subjective well-being also significant for the two items indicated by $\mathrm{R}=0.291$ (network density) and $\mathrm{R}=0.125$ (organizational membership). These effect sizes indicate that, to some extent, one's network density and being an active member of an organization leads to happiness.

\subsection{Ordinary Least Square (OLS) multiple regression on Subjective Well-Being}

For the core analysis, an Ordinary Least Square (OLS) multiple regression is performed. This analysis allows us to predict the value of dependent variables from the value of independent variables. In the case of this study, we want to mainly look at the value of subjective well-being predicted by active citizenship. In addition, in other models more variables are also taken into account, thus multiple regression analysis will be performed. The estimation of the first model (Model 1) with active citizenship as the predictor. The second model (Model 2) will also include the explanatory variables of network density, organization membership, offline interaction, gender, level of education, religiosity, and domicile. Lastly, the third model (Model 3) will include all explanatory and the interaction variables. An extended regression analysis with 10 models will also be performed, in order to further test for multicollinearity as well as to assess the gradual change of effect sizes of the main association between active citizenship and subjective well-being.

Table 6. Multiple regressions result for Subjective Well-Being

\begin{tabular}{llll}
\hline & Model 1 & Model 2 & Model 3 \\
\hline Intercept & $5.938 * * *$ & $5.812 * * *$ & $5.132 * * *$ \\
& $(0.117)$ & $(0.212)$ & $(0.368)$
\end{tabular}


Active citizenship
$0.587^{* * *}$
$0.313^{*}$
$0.910^{*}$
(0.110)
(0.123)
(0.426)

Social Capital Moderators

Network size

$0.258 * * * \quad 0.228$

(0.068)

(0.138)

Organizational membership

0.112

0.257

(0.122)

(0.244)

Online interaction

$-0.258 *$

$-0.720^{*}$

(0.111)

(0.247)

Socio-demographic Moderators

Female

$-0.154$

0.311

(0.106)

(0.251)

Level of education

$0.264^{*} \quad 0.597 *$

(0.089)

(0.202)

Religiosity

$0.170^{*}$

0.137

(0.067)

(0.139)

City domicile

$\begin{array}{ll}0.177 & -0.195 \\ (0.118) & (0.288)\end{array}$

Interaction effects

Active citizenship*network size

Active citizenship*organizational membership $-0.020$

Active citizenship*online interaction

$-0.088^{*}$

(0.039)

Active citizenship*female

$-0.081^{*}$ (0.038) 
Active citizenship*religiosity

\begin{tabular}{llll}
\hline R-squared & 0.086 & 0.200 & 0.239 \\
Adjusted R-Squared & 0.083 & 0.179 & 0.199
\end{tabular}

a. Dependent Variable: SWB

b. Ordinary Least Squares Multiple Regression

c. Value $* \mathrm{p}<0.05 ;{ }^{* *} \mathrm{p}<0.01 ; * * * \mathrm{p}<0.001$

In model 1, a linear regression was calculated to predict subjective well-being based on active citizenship. A significant regression equation was found $(\mathrm{F}(1,303)=28.575, \mathrm{p}<.000)$, with an $\mathrm{R}^{2}$ of 0.086 . The predicted subjective well-being is equal to $5.938+0.587$, where active citizenship was constructed in a single variable which ranges between $0-2$. Subjective well-being increased by 0.587 for an increase of 1 unit of involvement in active citizenship activities.

In model 2, a linear regression was calculated to predict the direct effect of other independent variables of social capital and socio demographic on subjective well-being, controlling for active citizenship. In this model, coefficient for active citizenship is still significant with effect size of 0.313 , smaller in comparison to the effect size in model 1 . The main effects are significant for network density, frequent online interaction, level of education, and religiosity. The regression equation is $(\mathrm{F}(8,296)=9.264, \mathrm{p}<.000)$, with an $\mathrm{R}^{2}$ of 0.200 . The predicted subjective well-being is equal to $4.924+0.313$ (active citizenship) +0.258 (network size) 0.258 (online interaction) +0.264 (education) +0.170 (religiosity), with network density coded as $0=<50$ people, $1=50-100$ people, $2=>100$ people; offline (0) /online (1) interaction is a dichotomous variable, education coded as $0=$ high school degree, $1=$ bachelor's degree, $2=$ masters degree, and 3=doctorate degree; and religiosity is being coded between 0 3. Subjective well-being among active citizens increased by 0.258 for an increase of 1 unit in one's network; by 0.264 for an increase of 1 unit in level of education and by 0.170 an increase of 1 unit in religiosity. As for an increase in 1 unit of online interaction relative to the offline interaction, subjective well-being decreased by 0.258 .

In model 3, a linear regression was calculated to predict subjective well-being based on the moderating effects of independent variables, while at the same time being controlled for their direct effect. In this model, coefficient for active citizenship is still significant and increased from the first two models, with effect size of 0.910 , indicating the moderating variables are strengthening the association between active citizenship and subjective well-being. While the main effects are still significant for level of education as well as online interaction on subjective well-being. With regard to the interaction effect, the effect sizes are significant for 
active citizenship*online interaction, and active citizenship*female. The regression equation is $(\mathrm{F}(15,289)=4.528, \mathrm{p}<.000)$, with an $\mathrm{R}^{2}$ of 0.239 . The predicted subjective well-being is equal to $5.132+0.910$ (active citizenship) -0.720 (online interaction) +0.597 (education) 0.088 (active citizenship*online interaction) - 0.081 (active citizenship*female). Subjective well-being among active citizens frequently interacting online are lower in relative to those who are frequently interacting offline, controlling for other predictors. Moreover, subjective well being is lower among female active citizens in relation to male (see appendix for graph on the interaction effects).

To further test for multicollinearity, an extended regression analysis with 10 models is also performed on all of the variables (see appendix for the regression table). The analysis result indicates the effect size of active citizenship on subjective well-being is shown to be changing in between models. The effect sizes are strongest in the last three models, in which the interaction effects are included. In this case, the moderating effect of offline/online interaction and gender are statistically significant to strengthen the association between active citizenship and subjective well-being.

From these analyses, we can say that, first, active citizenship does contribute to subjective well-being, thus the null hypothesis is being rejected. Second, network density, online interaction, level of education and religiosity does have a direct effect on subjective well-being, controlling for active citizenship. Third, the interaction effect indicates happiness is lower among active citizens who are more often interacting online in comparison to those who are more often interacting offline. While female active citizens are shown to be less happier in comparison to male active citizens. These results on the interaction effects contradicts the hypotheses formulated in this study.

\section{4 - Conclusions and Recommendations}

The general purpose of this study is to further understand the concept of subjective well-being, by integrating sociological concepts. Studies on subjective well-being is somewhat still limited in Indonesian context, let alone to integrate sociological concepts. In this study, we look at active citizenship in explaining subjective well-being among the Indonesian millennials. Active citizenship is by product of the Indonesian emerging democracy, characterized by the rich associational life, as well as the context of diverse society. Active citizenship has been transforming in terms of the paradigm and values, given the different context that applies for different Indonesian generations. Thus, we aim to answer whether active citizenship is associated with subjective well-being, and does the association further strengthened by the interaction effects of social capital (network size, organizational membership, offline/online interaction), and socio-demographic determinants (gender, level of education, religiosity, place of domicile).

From this study, it is indicated that the respondents generally have relatively high subjective well being. Results from the analysis confirms that active citizenship does contribute to their subjective well-being. Moreover, offline/online interaction and gender are confirmed to have interaction effects on the association between active citizenship and subjective well-being. For the former, the main effect is also confirmed, where females are less happy relative to male. Whereas network size, religiosity, and level of education have positive main effects on subjective well-being. Through active citizenship, people of diverse socio-economic backgrounds are able to cooperate and serve for greater good. Active citizenship at the collective level serves as the ties that binds people of diverse ethic and socio-cultural backgrounds (bhinneka) to cooperate in the value of solidarity (gotong royong) to maintain 
unity (tunggal), which is also embodied in Indonesian national motto, unity in diversity (bhinneka tunggal ika). Collectively, people are making progress for communities (i.e alleviating poverty, creating inclusive society, strengthening civic skills, etc), and individually, there are multiple gains from these involvements which contributes to one's subjective well-being. Active citizenship increases mutual trust and support between individuals, thus enabling them to access the available resources within the network in order to get by or move forward.

The findings of this study should contribute to the existing discussions on the subjective well-being of Indonesian millenials. Identifying determinants of subjective well-being perhaps, may require a collaborative effort, given the heterogeneous nature of the Indonesian society. Young people coming from different regions of Indonesia may have different perceptions on the essential aspects that construct their subjective well-being. Given the various socio-economic backgrounds influencing the individuals as well as the social conditioning in their communities, some Indonesian millennials are united by some shared values (i.e solidarity, sense of belonging, etc). Taking these conditions into account, we are taking part in the discussion by discovering how being actively involved in communities leads to subjective well-being. We believe that both topics of subjective well-being and active citizenship are some of the important attributes to the Indonesian millennials generation in facing contemporary challenges. Our study on happiness should give further insights on the mental and emotional states of the generation that will help communities moving forward. While we consider active citizenship as the action taken to make communities a better place. Furthermore, this study should provide some new insights on the mechanisms explaining subjective well-being, also by taking into account other determinants being discussed. Thus, specific determinants of subjective well-being are covered in this study, while there are many other social determinants that are worthwhile to be explored.

The study on the subjective well-being will need to be further developed, and to focus on the millennials age group is still an open option. Moving forward, young Indonesians will be faced with more challenges and are likely to be more complex, occurring both at the national and global level. Active citizenship will continue to be practiced and flourished in societies as one means of addressing these challenges. Thus, conducting similar study is still likely to be relevant. Based on what has been done in this study, there are several recommendations for future similar studies. Some important aspects such as sample size and variable operationalization are not adequately fulfilled in this study. This study might not be representative to the whole population given the small sample size. Given the large, heterogenous, and widespread population of Indonesian, a well-planned sampling is required for the research to be representative to the whole population. Variable operationalizations are also required to precisely measure concepts based on the relevant high-profile literatures. Thus, refined or more determinants should be considered to give better insights on the state of subjective well-being of the Indonesian millennials. By taking this approach, more analyses could be modelled and the result could explain more on the association between active citizenship and subjective well-being, particularly for the interaction effects that enhance the association. 


\section{References}

Armenta, Christina M, Peter M Ruberton, Sonja Lyubemirsky. (2015). Subjective Well-being, Psychology of. International Encyclopedia of the Social \& Behavioral Science: 648 - 652, (2nd edition, Volume 23).

Barber, Terry. (2009). Participation, Citizenship, and Well-Being. Nordic Journal of Youth Research, Vol. 17 (1) : $25-40$.

Badan Pusat Statistik Indonesia (Indonesian National Bureau of Statistics). (2017). Indeks Kebahagiaan 2017. Badan Pusat Statistik.

Badan Pusat Statistik Indonesia (Indonesian National Bureau of Statistics). (2018). Profil Generasi Milenial Indonesia (Indonesian Millennial Generation Profile). Badan Pusat Statistik.

Bryant, Fred B. \& John T. Marquez. (1986). Educational Status and the Structure of Subjective Well-Being in Men and Women. Social Psychology Quarterly. Vol. 49 (2), pp. 142 $-153$.

Deci., Edward L. \& Richard M. Ryan. (2006). Hedonia, Eudaimonia, and Well-Being : An Introduction. Journal of Happiness Studies 9:1 - 11 .

Diener, Ed. (1984). Subjective Well-Being. Psychological Bulletin 3: 542 - 575.

Diener, Ed, et. al. (1995). Factors Predicting the Subjective Well-Being of Nations. Journal of Personality and Social Psychology. Vol. 69. No.5, 851-864.

Dusuki, Asyraf Wajdi. (2006). Ibn Khaldun's Concept of Social Solidarity and Its Implication to Group-Based Lending Scheme. A paper presented at Monash University 4th International Islamic Banking and Finance Conference.

Gaag, M. P. J. V. D. (2005). Measurement of Individual Social Capital. [S.1.]: [S.n.].

Green, Melanie C \& Timothy C. Brock. (2005). Organizational Membership versus Informal Interaction : Contributions to Skills and Perceptions that Build Social Capital. Political Psychology, Vol. 26, No.1.

Hall, Tom, et. al. (2000). Young People, Citizenship, and the Third Way : a Role for Youth Service. Journal of Youth Studies. Vol.3, No.4, $461-471$.

Helliwell, John F. (2001). Social Capital, the Economy, and Well-Being. The Review of Economic Performance and Social Progress: $43-60$.

Helliwell, John F, Haifang Huang. (2013). Comparing the Happiness Effects of Real and On-line Friends. National Bureau of Economics Research (NBER) Working Paper Series: Working Paper 18690, http://www.nber.org/papers/w18690.

Helliwell, John F, Robert D. Putnam. (2004). The Social Context of Well-Being. The Royal Society $359: 1435-1446$.

Hikam, A.S. (2000). Islam, Demokratisasi \& Pemberdayaan Civil Society. Penerbit Erlangga. Jakarta, Indonesia. 
Hrotko, Joao, et. al. (2019). Measure Well-Being to Improve It. The 2019 Sustainable Economic Development Assessment (SEDA) by the Boston Consulting Group.

IDN Research Institute. (2019). Indonesian Millennials Report 2019. Publication by IDN Times.

Jackson, Matthew O. (2019). The Human Network: How Your Social Position Determines Your Power, Beliefs, and Behaviors. First edition, Pantheon Books. New York, USA.

Kapucu, Naim. (2011). Social Capital and Civic Engagement. International Journal of Social Inquiry Vol. 4, No. 1, pp. $23-43$.

Lim, Chaeyoon \& Robert D. Putnam. (2010). Religion, Social Networks, and Life Satisfaction. American Sociological Review 75(6) 914-933.

Lindstrom, Lisbeth. (2010). Youth Citizenship and the Millennium Generation. Citizenship, Social and Economics Education. Vol. 9, No.1.

Lussier, Danielle N and Steven M. Fish. (2012). Indonesia : The Benefits of Civic Engagement. Journal of Democracy Vol. 23, No.1.

Milligan, Christine \& Nicholas R. Fyfe. (2005). Preserving Space for Volunteers : Exploring the Links between Voluntary Welfare Organizations, Volunteering and Citizenship. Urban Studies, Vol. 42 (3), pp. $417-433$.

Nickki J. Pearce \& Reed W. Larson. (2006). How Teens Become Engaged in Youth Development Programs: The Process of Motivational Change in a Civic Activism Organization, Applied Developmental Science, 10:3, 121-131.

Nurdiyanti, Aina \& Karim Suryadi. (2019). Digital Philanthropy in Indonesia : Strengthening Civic Virtue for Digital Citizens. Advances in Social Science, Education, and Humanities Research, vol. 317.

Scholzman et. al., (1995). Gender and Citizen Participation: Is There a Different Voice?. American Journal of Political Science, Vol. 39, No. 2.

Suh, E. M., \& Oishi, S. (2002). Subjective Well-Being Across Cultures. Online Readings in Psychology and Culture, 10(1).

Puntscher, Sibylle, et al. (2014). The Impact of Social Capital on Subjective Well-Being : A Regional Perspective. Journal of Happiness Study Vol.16 : 1231 - 1246.

Ram, Rati. (2009). Social Capital and Happiness : Additional Cross-Country Evidence. Journal of Happiness Study $11: 409-418$.

Rostianti, Rokhima, et. al., (2014). Understanding Social Enterprises in Indonesia : Drivers and Challenges. Journal of Indonesian Economy and Business. Vol. 29 (2), pp. 183 - 191.

Schultz, Lisa et. al. (2009). Global Connections: 'A Tool for Active Citizenship'. Development in Practice, 19:8, 1023 - 1034.

Tay, Louis, et. al. (2014). Religiosity and Subjective Well-Being : an International Perspective. In Religion and Spirituality Across Cultures, Cross-Cultural Advancements in Positive Psychology 9. Springer Science and Business Mendia, Dordrecht 2014. 
Tov \& Diener. (2008). The Well-Being of Nations: Linking Together Trust, Cooperation, and Democracy, Cooperation: The Political Psychology of Effective Human Interaction, Wiley-Blackwell Publishing.

Thoits, Peggy.A \& Lyndi N. Hewitt. (2001). Volunteer Work and Well-Being. Journal of Health and Social Behavior; Vol. 42, No.2, pp. $115-131$.

United Nations Population Fund (UNFPA). (2014). Indonesian Youth in the 21st Century. UNFPA Indonesia.

Veenhoven, Ruut. (2008). Sociological Theories of Subjective Well-Being. In "The Science of Subjective Well-Being : A Tribute to Ed Diener", Guilford Publications, New York, pp. 44-61.

Vriens, Eva \& Erik van Ingen. (2018). Does the Rise of Internet Bring Strong Ties? Analyses of Social Media Use and Changes in Core Discussion Network. New Media and Society, Vol.20 (7) $2432-2449$.

World Economic Forum. (2019). Why the Future of Well-Being Isn't About Money. Futurity. https://www.weforum.org/agenda/2019/02/the-future-of-well-being-isn-t-about-money.

World Economic Forum. (2017). What's global citizenship? https://www.weforum.org/agenda/2017/10/why-the-world-needs-more-global-citizens.

Yakovlev, Pavel \& Susane Leguizamon. (2012). Ignorance is Not Bliss : on the Role of Education in Subjective Well-Being. The Journal of Socio-Economics, Vol. 41 (6), pp. 806 815.

Yani, Andi Ahmad, Andi Rahmat Hidayat. (2018). What is the Citizenship Quality for Our Community? Measuring Active Citizenship. Public Administration Issue: Special Issue II.

Zepke, Nick. (2013). Lifelong Education for Subjective Well-Being : How do Engagement and Active Citizenship Contribute?. International Journal of Lifelong Education. Vol. 32, 2013 - Issue 5.

Zweig, Jacqueline S. (2014). Are Women Happier than Men? Evidence from the Gallup World Poll. Journal of Happiness Study 16: 515 - 541. 


\section{Appendixes}

Appendix 1. Interaction effect between active citizenship and online/offline interaction on subjective well-being.

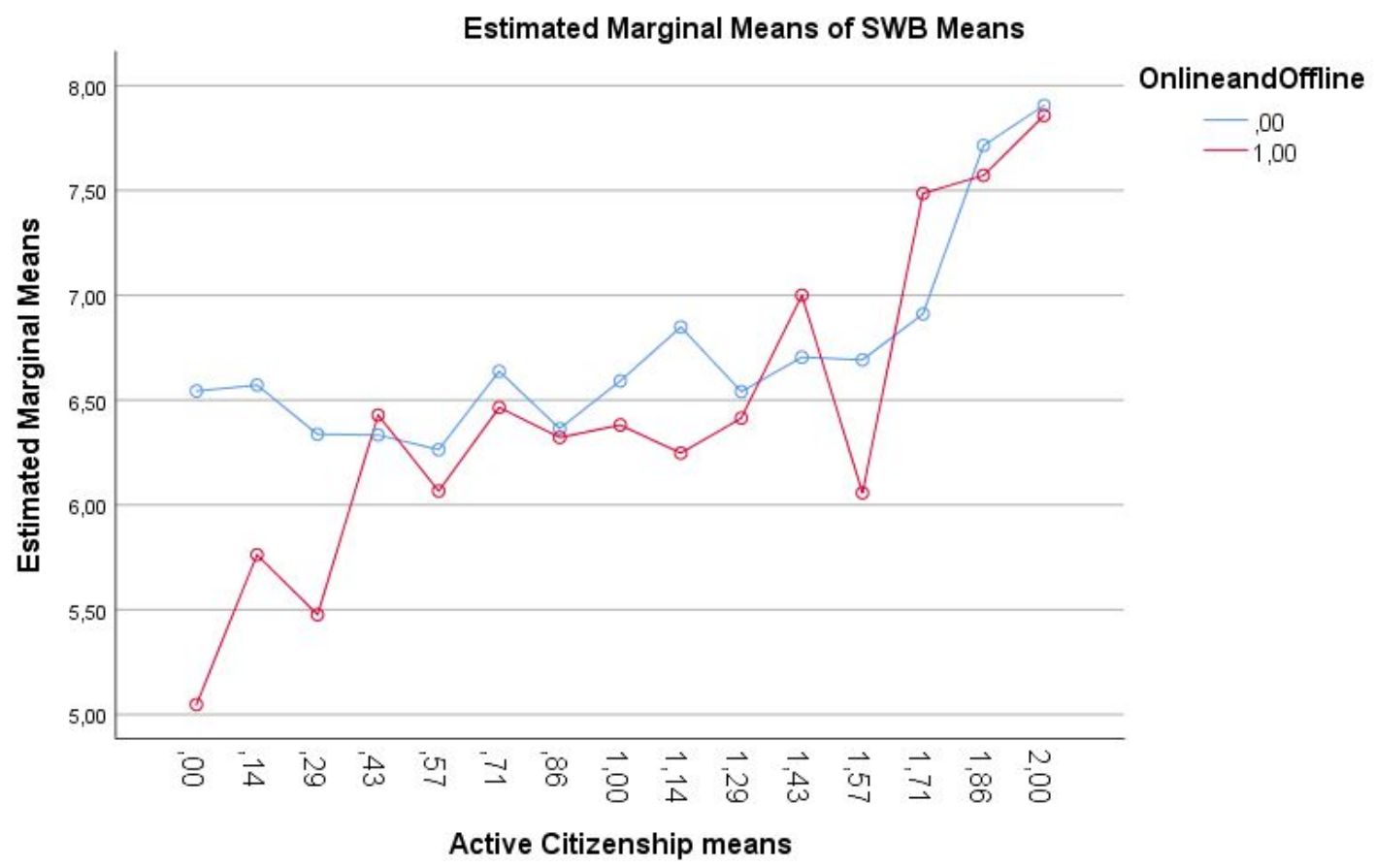

Coding : $0=$ offline interaction, $1=$ online interaction

Appendix 2. Interaction effect between active citizenship and female/male on subjective well-being.

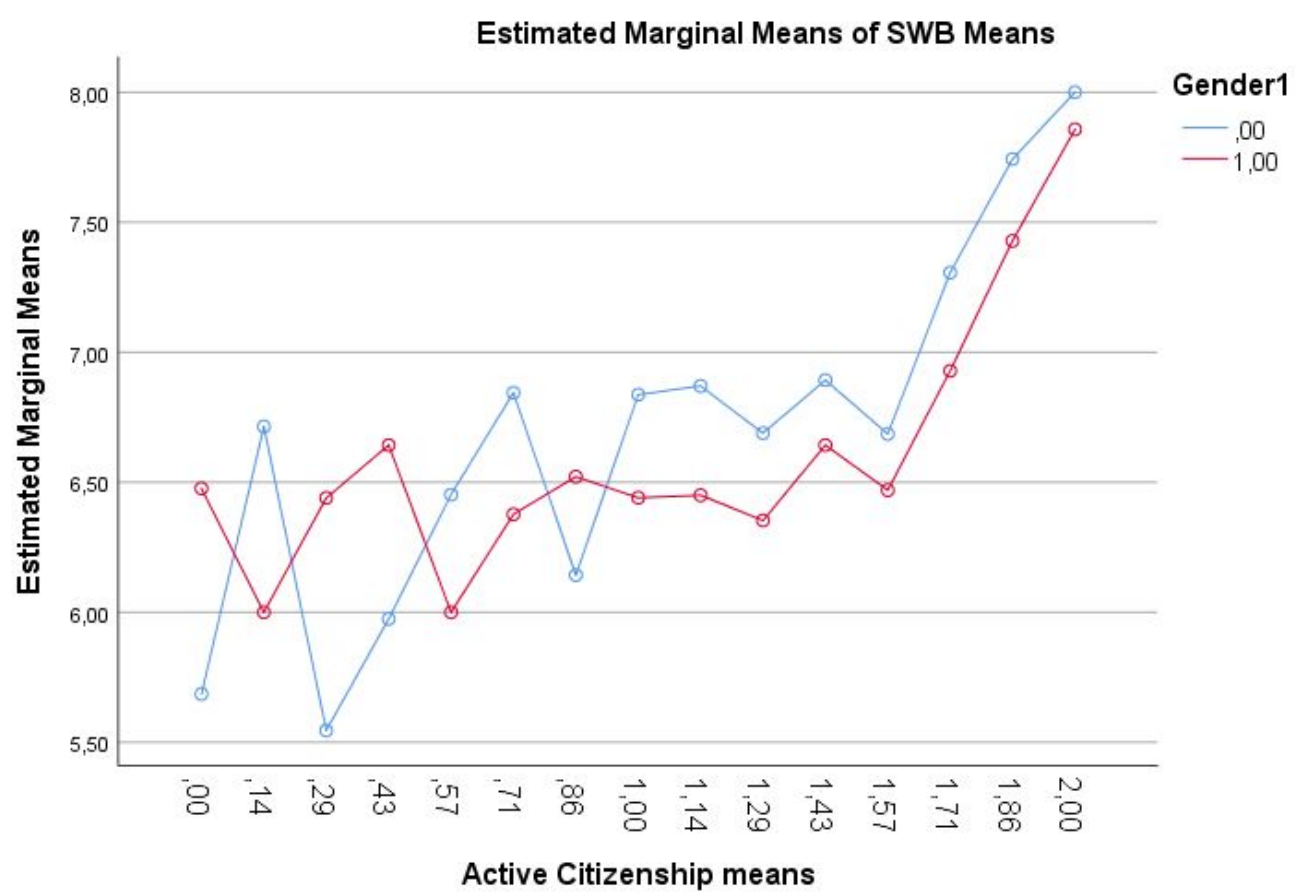

Coding : $0=$ male, $1=$ female 
울

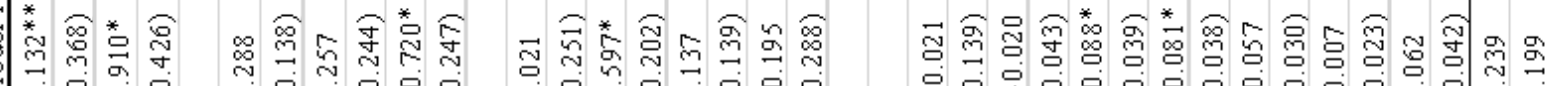

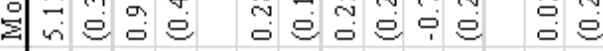

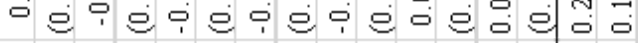

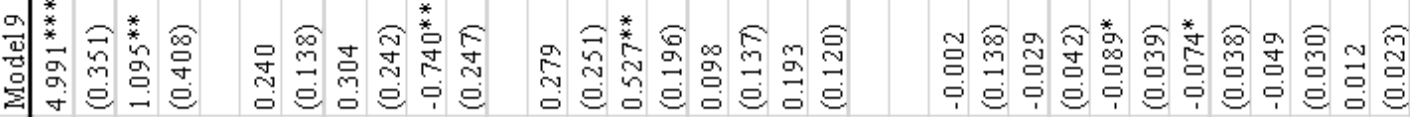

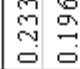

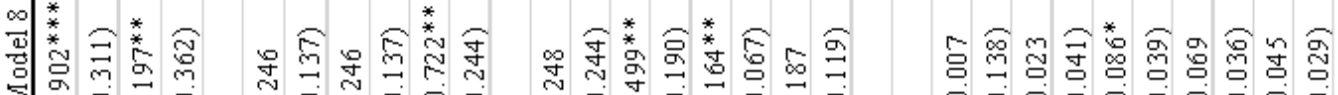

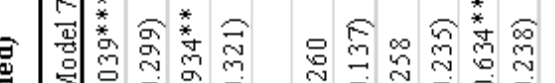

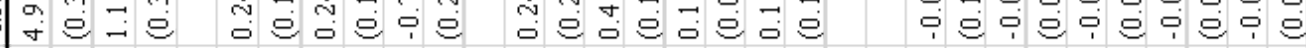

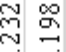

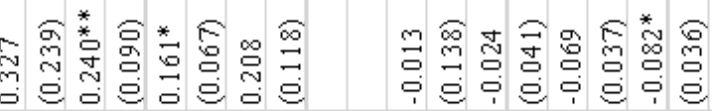

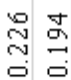

$+\frac{*}{*}$

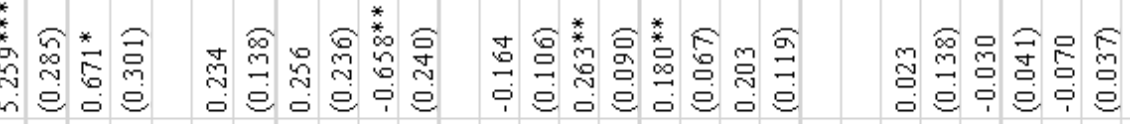

$\stackrel{\sim}{\sim} \underset{\infty}{\stackrel{\infty}{\sim}} \stackrel{\infty}{\sim}$

约草

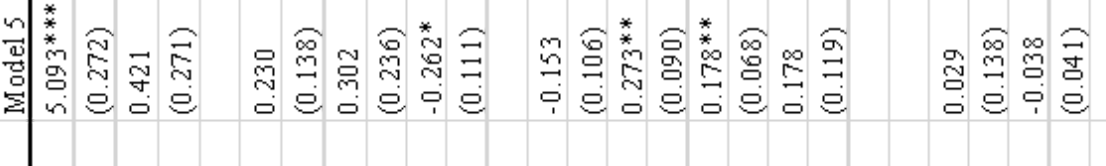

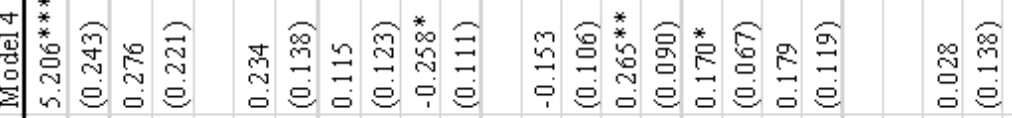

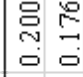

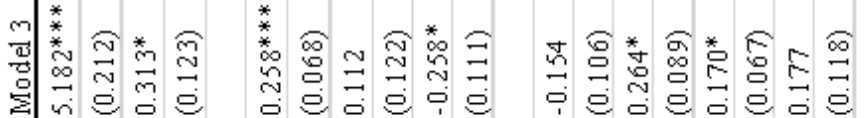

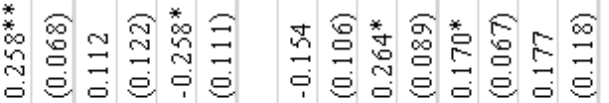

总 $\underset{0}{\stackrel{2}{0}}$

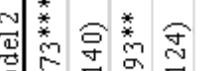

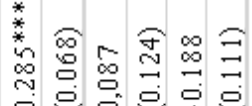

骂恕

sis

o

:

或莘等意合

$+|+|$

꼻

$\stackrel{8}{5}$

事的果

$\stackrel{\circ}{\circ} \stackrel{\circ}{\circ}$

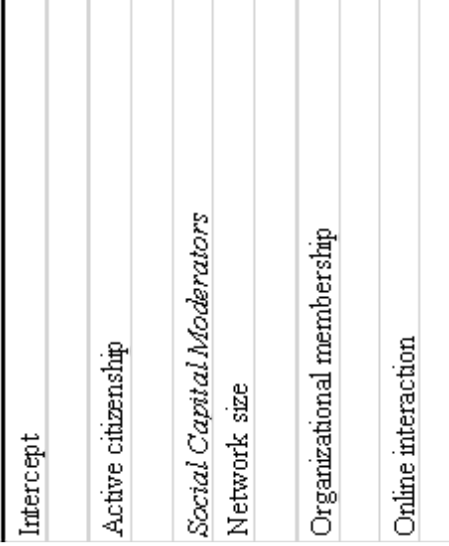

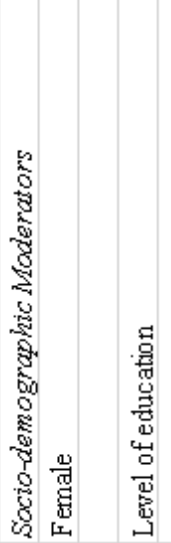

Dependent Variable: SWB

b. Ordinary Least Squares Multiple Regression

c. Value $* \mathrm{p}<0.05 ; * * \mathrm{p}<0.01 ; * *$ p $<0.001$ 